\title{
Animal Models of Alzheimer's Disease: Behavior, Pharmacology, Transplants
}

\author{
V. Haroutunian, P.D. Kanof, G.K. Tsuboyama, G.A. Campbell and K.L. Davis
}

\begin{abstract}
Physostigmine, oxotremorine, RS-86, and a combination of piracetam and lecithin, have all been studied in patients with Alzheimer's disease. Intravenous physostigmine produced a significant improvement in patients' ability to recognize words and particularly to distinguish words they had never seen before from words previously presented. A subgroup of Alzheimer's patients had a clinically meaningful improvement to treatment with oral physostigmine, with the degree of improvement correlating with the ability of oral physostigmine to increase the nocturnal secretion of cortisol. No statistically significant differences of piracetam or piracetam and lecithin, compared to placebo were noted, however, the ratio of red cell to plasma choline might be associated with treatment responsivity. The potential therapeutic efficacy of oxotremorine proved all but impossible to assess due to concomitant adverse effects, particularly dysphoria. Results with another cholinergic agonist, RS-86, will be reported. This drug appeared to be better tolerated than oxotremorine.

Animals with a kianic acid induced cortical depletion of choline acetyltransferase were found to have a significant impairment in retention of a passive avoidance task, an abnormality that was readily reversible by physostigmine, oxotremorine and 4-amino-pyridine. Cysteamine, a depletor of somatostatin, also produced a comparable deficit.
\end{abstract} RÉSUMÉ: Etude de substances cholinomimétiques dans la maladie d'Alzheimer et chez des modèles animaux. La
physostigmine, l'oxotrémorine, le RS-86 et une association de piracetam et de lécithine sont toutes des substances qui
ont été étudiées chez les patients souffrant de la maladie d'Alzheimer. La physostigmine par voie intraveineuse a
produit une amélioration significative dans la capacité des patients à reconnaître des mots, spécialement à distinguer
des mots qu'il n'avaient jamais vus de mots qu'on leur avait déjà présentés. Un sous-groupe de patients atteints de la
maladie d'Alzheimer ont bénéficié d'une amélioration cliniquement appréciable lors d'un traitement oral à la
physostigmine. Le degré d'amélioration était en corrélation avec la capacité de la physostigmine orale à augmenter la
sécrétion nocturne de cortisol. Nous n'avons pas noté de différence statistiquement significative entre le piracetam,
le piracetam associé à la lécithine et le placebo. Cependant, le rapport de la choline des globules rouges à la choline
plasmatique pourrait être associé à la sensibilité au traitement. Il s'est avéré impossible d'évaluer l'efficacité
thérapeutique potentielle de l'oxotrémorine à cause de ses effets secondaires fâcheux, notamment la dysphorie.
Nous rapporterons les résultats obtenus lors de l'utilisation d'un autre agoniste cholinergique, le RS-86. Ce médicament
semble être mieux toléré que l'oxotrémorine.
Can. J. Neurol. Sci. 1986: 13:385-393

Animal models of Alzheimer's Disease (AD) have in general been bound by several constraints. There are no known animals which show the characteristic neuropathological changes which are the hallmark of AD. There are also no known agents or procedures which will induce all of the features of $A D$ in animals. Progress in the development of animal models of $A D$ has been greatly aided by the description of the neurochemical sequelae of $\mathrm{AD}$ in recent years. The characterization of the neurochemical deficits in AD has led to the development of procedures which can duplicate some aspects of AD in mammals. It must be noted at the outset however, that the absence of naturally occurring $\mathrm{AD}$ in lower species severely constrains the ability of animal models to reflect all aspects of the disease process. Even if an animal model could be developed which mirrored all the known neurochemical and neuropathological aspects of the disease process, it would still only reflect those aspects of AD which have been characterized thus far. This article will discuss the results of animal studies which have attempted to model some aspects of the disease process, as well as studies which have attempted to reverse the deficits induced in the model systems.

The recent reports by several authors implicating specific deficits in brain neurotransmitter systems of AD patients, and the demonstrations of dramatic degeneration of cholinergic neurons in the basal forebrain of these patients, have focused most animal model studies on brain cholinergic, noradrenergic and somatostatinergic systems. This paper discusses the results of some of the studies which have attempted to describe a) the behavioral consequences of experimentally induced deficits in these neurotransmitter systems, and b) some potential approaches towards the alleviation of the behavioral deficits produced.

\section{A. Animal models of cholinergic system deficits}

Whitehouse et al' reported a paucity of large cell bodied, acetylcholinesterase positive neurons in the basal forebrain (nucleus basalis of Meynert) of AD patients relative to similarly aged non-AD controls. The degeneration of these cholinergic neurons in $\mathrm{AD}$ has now been confirmed by several authors. ${ }^{2.3}$ 
At approximately the same time, it was reported $4,5,6,7$ that the majority $(70-80 \%)$ of cholinergic activity in the cerebral cortex could be traced to cells in the basal forebrain. It is now well established that the cholinergic cells of the basal forebrain extend their axons in a topographic manner to the cerebral (and hippocampal) cortex, providing the major cholinergic input to the cortex. These findings led to a neuroanatomical explanation for the reports of profound deficits in cortical cholinergic markers in $\mathrm{AD}^{8.9 .10}$ and gave impetus to the "cholinergic hypothesis" of Alzheimer's disease. "This hypothesis has led to a flurry of studies attempting to model the cholinergic deficits of $A D$ in animals by experimentally lesioning the basal forebrain. ${ }^{12,13,14,15}$ Such studies have been in universal agreement. Lesions of the nucleus basalis of Meynert ( $\mathrm{nbM}$ ) area in rats and monkeys lead to deficits in cortical markers of $\mathrm{AD}$ as well as producing a profound impairment of "cognitive" function.

Several authors ${ }^{5.12 .13 .15}$ reported that lesions of the nbM (whether caused by excitotoxic or electrolytic lesion procedures) result in significant (30-50\%) depletions in cortical markers of cholinergic activity such as choline acetyltransferase and acetylcholinesterase. These lesions are neurochemically specific and do not affect markers for other transmitter systems. In addition, lesions of the nbM are stable over time with little or no spontaneous post-lesion recovery of cholinergic activity or behavioral deficits. ${ }^{17.18}$ Animals with nbM lesions show profound behavioral (learning and memory) deficits on most tests. These deficits are clearly apparent on tests of passive avoidance retention. For example, in one study we lesioned the nbM of rats with ibotenic acid fourteen days prior to passive avoidance training. During training the rat was placed in the lit compartment of a light/dark shuttle box and was given access to the dark compartment of the shuttle box. Upon entry into the dark compartment each rat received a single mild $(0.5 \mathrm{~mA})$ foot-shock. When returned to the passive avoidance apparatus 72 hours later, the nbM lesioned rats showed a profound amnesia for the shock experience and crossed into the shock compartment as readily as they had prior to the training episode. Sham operated rats on the other hand avoided the shock compartment. These results are shown in Table 1. Similar deficits have been found on measures of active avoidance, ${ }^{13}$ radial maze performance, ${ }^{19}$ and tests of $\mathrm{T}$-maze alternation and memory. ${ }^{20}$ A recently conducted experiment in our laboratory, using a T-maze alternation paradigm can serve as a case in point. Eighteen rats with excitotoxic (5ug ibotenic acid in lul of PBS) lesions of the $n b M(n=6)$, excitotoxic lesions of the medial septum $(n=6)$, or sham lesions $(n=6)$ were tested in a T-maze alternation paradigm. The animals were trained to traverse and enter the goal boxes of the T-maze for food reward (weight reduced to $85 \%$ of matched controls, reinforced in the T-maze with Froot Loops). Once the animals learned to perform in the T-maze, a forced alternation procedure was imposed. Each trial consisted of two phases. In Phase one, one arm of the T-maze was blocked and the rat was required to enter the second goal box for reinforcement. After the reinforcement was obtained, the rat was removed from the maze, access to both arms was made available, and the goal box opposite to the reinforced arm in Phase one was baited (this procedure took approximately 15 seconds). The rat was then placed back into the start compartment of the T-maze and was allowed to run the maze for reinforcement. If the rat entered the baited goal box (the box opposite to where reinforcement had been obtained in
Phase one, i.e. win shift), it was permitted to stay and consume the reinforcement. If the rat entered the box visited in Phase one, it was immediately removed from the maze (non-correction procedure). Each rat received six such two phase trials each day until a criterion of two consecutive days of errorless responding was reached. The number of trials required to reach criterion by the 3 groups is presented in Table 2. Rats with ibotenic acid induced $\mathrm{nbM}$ lesions or medial septal (MS) lesions required many more $(\mathrm{ps}<.05)$ trials to learn this response (it should be noted that the nbM lesioned rats performed better in this experiment than in a previous pilot study where the nbM lesioned rats failed to reach the acquisition criterion even after 40 consecutive days of training). Similar results have been reported by others using similar test procedures. ${ }^{21.22}$ Once the acquisition criterion was reached, the test paradigm was changed by introducing delays between phase one and phase two on three of the six daily trials. These delays lasted 1, 5, or 15 minutes. The rats were tested by this procedure for four days. Performance accuracy on these delay trials averaged over the first two days is shown in Figure 1. This figure shows that all animals suffered a performance decrement when the delay between Phase one and Phase two was greater than one minute. The lesioned rats however, showed significantly greater impairment than sham operated controls when a five minute delay interval was imposed. These results indicate that the nbM and MS lesioned rats suffer from an acquisition as well as a retention deficit relative to sham operated controls. The many studies showing nbM-lesion induced deficits in learning and memory taken together suggest that the degeneration of cholinergic nbM neurons contribute to some of the cognitive deficits observed in AD.

\section{B. Animal models of central somatostatinergic deficits}

Cortical cholinergic deficits are by no means the only consistent deficits found in AD. Many other neurotransmitter and neuromodulator systems appear to be involved. Decreased cortical somatostatin-like-immunoreactivity (SLI) is an example of another profoundly perturbed system in AD. Several reports have shown that SLI as well as somatostatin receptors are significantly reduced in post-mortem samples of cortex in AD. ${ }^{23.24 .25}$ The relationship between brain SLI and behavior, especially learning and memory, has received little attention. Unlike the cholinergic system, somatostatinergic cells appear to be distributed relatively evenly throughout the brain. ${ }^{26.27}$ There are no specific loci within the brain which can be lesioned

Table 1: Effect of $\mathbf{n b M}$ lesions on the 72 hour retention of passive avoidance. Results expressed as mean crossthrough lateny in seconds \pm SEM

\begin{tabular}{lc}
\hline \hline Sham Lesioned & $270.2( \pm 77)$ \\
nbM Lesioned & $66.8( \pm 18)^{*}$ \\
\hline
\end{tabular}

${ }^{*} \mathrm{p}<0.01$

Table 2: Effect of nbM and medial septum (MS) lesions on mean number of trials to criterion $( \pm$ SEM) on a T-maze alternation task

$\begin{array}{ll}\text { Sham Lesioned } & 13.0( \pm 1.2) \\ \text { MS Lesioned } & 22.4( \pm 3.2) \\ \text { nbM Lesioned } & 20.5( \pm 2.05)\end{array}$


to produce general decreases in cortical SLI. The somatostatin content of the brain can, however, be manipulated pharmacologically. Cysteamine (2-mercaptoethanolamine) is an agent which when administered systemically to rats causes a reversible, yet profound (approximately 50\%), decrease in brain SLI. In a recent study, ${ }^{28}$ we have shown that the administration of cysteamine to rats immediately following the acquisition of a passive avoidance response results in a dose dependent decrement in retention test performance 72 hours later (Figure 2). It is important to note that cysteamine at high doses $(150 \mathrm{mg} / \mathrm{kg}$ and up) does cause changes in central catecholaminergic markers (dopamine- $\beta$-hydroxilase), ${ }^{29}$ but passive avoidance retention deficits are apparent at lower, presumably SLI specific doses. These results are in general agreement with previously published work showing cysteamine-induced learning and memory deficits. ${ }^{30,31}$

At face value, these findings imply that the SLI deficits described in AD may also contribute to the cognitive decline characteristic of this disease; however, many more studies, employing agents with a greater specificity for somatostatinergic systems need to be conducted before any firm conclusions are reached. Preliminary work now underway in our laboratory suggests the presence of complex interactions between somatostatinergic systems and the cholinergic system of the basal forebrain. In three separate studies we have found that rats with lesions of the nbM do not suffer any greater memory impairment when a somatostatinergic deficit is superimposed upon the cholinergic lesion. In these studies nbM-lesioned and sham operated rats were trained on a one-trial passive avoidance paradigm with shock levels high enough $(0.8 \mathrm{~mA})$ to result in better than chance performance upon 72 hour retention testing of the $\mathrm{nbM}$ lesioned rats. Different groups of nbMlesioned and sham operated rats received $0,25,50$, or $150 \mathrm{mg} / \mathrm{kg}$

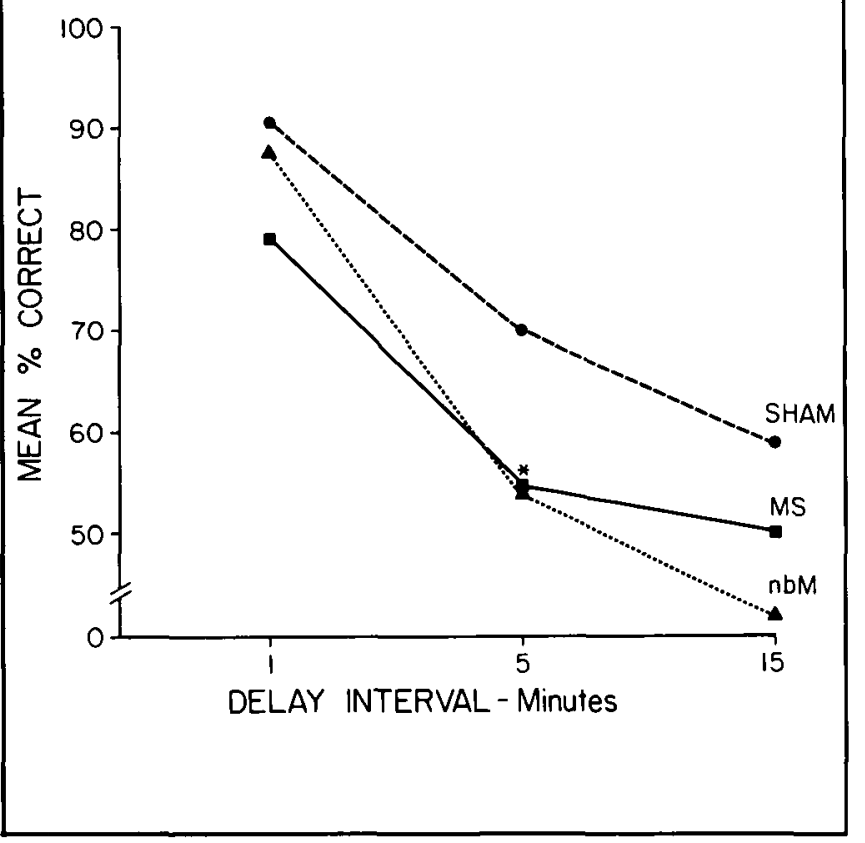

Figure I - Effect of delay intervals on the accuracy of T-maze alternation in nbM-lesioned, MS-lesioned and sham operated rats. ${ }^{*} v$ s. sham lesioned, $p s<0.05$ doses of cysteamine immediately following the acquisition trial. The performance of the sham operated rats was identical to the performance of the naive rats described above. Sham operated rats showed a profound cysteamine induced amnesia syndrome. The nbM lesioned rats however, despite receiving relatively high doses of cysteamine, failed to show additional cysteamineinduced deficits in passive avoidance test performance beyond those of nbM lesioned animals. Although this paradigm suffers from problems of proving the null hypothesis, it does suggest that somatostatinergic influences upon retention of passive avoidance may require an intact cholinergic system. If this hypothesis is proven to be true in future experiments, it would suggest that SLI deficits in AD may play a relatively minor role with respect to cognitive processes. The recently published work of Cutler et al ${ }^{32}$ found no somatostatin induced alleviation of cognitive deficits in AD patients, argues in favor of the above hypothesis, although these results could have been due to an inability to significantly increase central somatostatin concentrations and transmission following peripheral drug administration.

\section{Animal models of noradrenergic deficits}

Deficits in central noradrenergic function comprise yet another facet of $\mathrm{AD}$. It is now well established that a subset of younger AD patients show substantial noradrenergic deficits. ${ }^{33.34 .35}$ The extent to which the noradrenergic (NE) abnormality contributes to the cognitive deficits of AD remains to be resolved. Animal studies have failed to show evidence for global cognitive deficits resulting from central NE depletion. ${ }^{36.37 .38}$ It is however clear that lesions of the dorsal noradrenergic bundle often lead to changes in attentional processes, ${ }^{36}$ stress, ${ }^{39}$ rates of extinction, ${ }^{40}$ and perhaps most importantly, from an $\mathrm{AD}$ perspective (see below), changes in behavioral responses to cholinergic manipulations. With few exceptions, the available data suggests that if forebrain NE systems are involved in learning and memory, this involvement is limited to the more demanding learning situations. For example, forebrain NE depletions of $95 \%$ or more do not affect acquisition rates on a wide variety of tasks ranging from passive avoidance behavior to performance in complex mazes. ${ }^{41-44}$ In one experiment, we

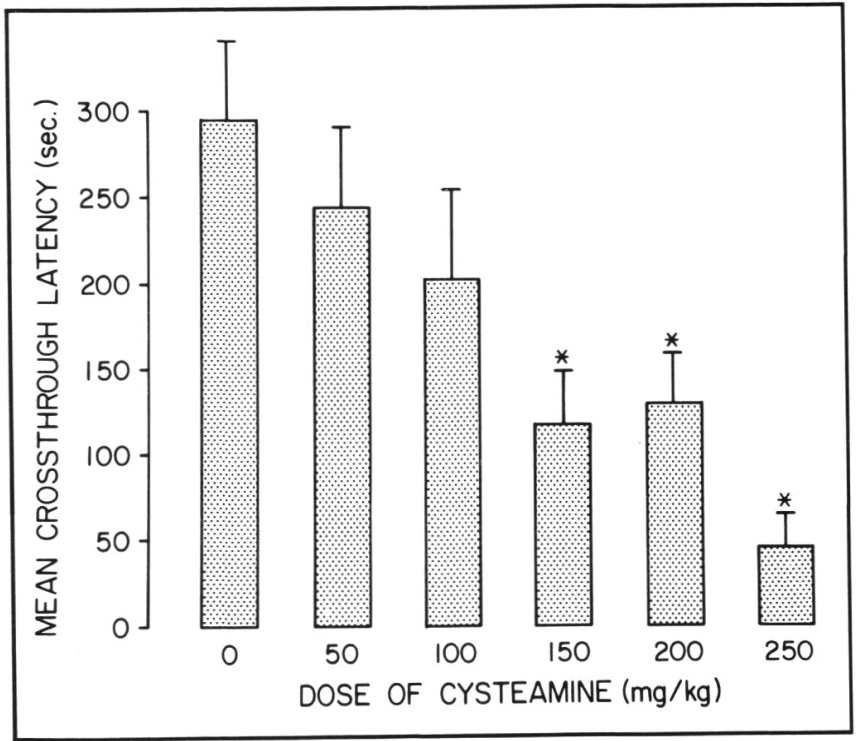

Figure $2-$ Effect of post-training administration of several doses of cysteamine on the 72 hour retention of passive avoidance. Results expressed as means and SEM. *vs. saline, ps<0.05 
lesioned the dorsal NE bundle two weeks prior to one trial passive avoidance training. When retention of passive avoidance was assessed 72 hours later, lesioned animals were indistinguishable from sham operated controls. Neurochemical examination of the cortex revealed that dorsal bundle lesions led to a mean NE depletion of $95 \%$. The lack of an NE lesion effect on passive avoidance learning and memory was underscored by the fact that 7 of the 12 animals lesioned in this study showed cortical NE levels which were below the sensitivity of the assay (sensitivity $=25 \mathrm{pg} \mathrm{NE}$ ) with no apparent passive avoidance learning and memory deficits. This finding stands in contrast to the effects of nbM lesions which produce severe learning and memory deficits even with cortical CAT depletions as small as $25 \%$ of controls.

There is evidence for forebrain NE system involvement in working memory tasks in monkeys..$^{45}$ Monkeys with neurotoxininduced lesions of the prefrontal cortex $\mathrm{NE}$ afferents are unable to perform delayed response tasks, ${ }^{45}$ while performance on tasks not involving working memory is unaffected. Evidence can also be cited for the involvement of cortical NE systems in the memory deficits observed in aged monkeys. ${ }^{45}$ Decreased levels of central catecholamines are consistently observed in aged vs young monkeys, ${ }^{46}$ which appear to be reflected in performance deficits on working memory tasks. These age related working memory deficits strongly resemble the deficits observed in young monkeys which have received neurotoxic lesions of prefrontal cortex NE afferents. Furthermore there is evidence showing that forebrain NE systems are affected by learning experiences. Forebrain NE levels are decreased, probably due to increased turnover rates, after aversive training situations ${ }^{47.48 .49}$ and the degree to which forebrain NE levels are decreased is predictive of and correlated with later retention of the learned response. Unfortunately, this decrease in forebrain NE is only found following learning situations with aversive stimuli and is not seen under conditions of appetitive reinforcement. ${ }^{50}$ These results suggest that it is the intensity of the individual animal's response to the training foot shock which is reflected in brain NE reductions rather than the learning event perse. There is also evidence that peripheral catecholamines can modulate the retention of learned events, ${ }^{38.51 .52}$ however the relevance of these findings to $\mathrm{AD}$ is less certain. It appears therefore that a direct primary involvement of central $\mathrm{NE}$ systems in learning and memory processes is unlikely, at least at a global level. It is nevertheless clear that central NE systems play an important role in the modulation of learning and memory.

\section{Alleviation of lesion-induced deficits}

There are several alternative strategies for the alleviation of lesion-induced deficits. Three such alternatives will be discussed in the following sections.

\section{Pharmacological reversal of lesion-induced deficits}

The pharmacological reversal of lesion-induced deficits has received the greatest attention. Our studies ${ }^{15}$ and those of oth$\mathrm{ers}^{21,22}$ have shown that nbM lesion-induced behavioral deficits are, at least partially, reversible by the administration of cholinergic drugs. Physostigmine, for example, has been repeatedly shown to normalize the learning and memory deficits induced by lesions of the nbM. In one such study ${ }^{15}$ physostigmine was administered $(0.03 \& 0.06 \mathrm{mg} / \mathrm{kg})$ systemically to $\mathrm{nbM}$-lesioned and sham-operated rats immediately after the acquisition phase of a one trial passive avoidance response. As Figure 3 shows, physostigmine enhanced the retention test performance of sham-operated and nbM-lesioned rats, but the dose of physostigmine required for enhancement of retention test performance was greater for nbM-lesioned than shamoperated rats. Physostigmine has been shown to enhance cholinergic lesion-induced behavioral deficits in other paradigms as well. Levy et $\mathrm{al}^{53}$ reported that the learning and memory deficits arising from cholinergic denervation (AF64A) of the hippocampus could be reversed by a $0.06 \mathrm{mg} / \mathrm{kg}$ dose of systemically administered physostigmine. Murray et $\mathrm{al}^{21}$ found that physostigmine administration can alleviate the nbM-lesion induced deficits which are manifest in a T-maze alternation paradigm. In a similar vein, we have found that a $0.06 \mathrm{mg} / \mathrm{kg}$ dose of physostigmine can normalize the memory deficits in nbM-lesioned rats apparent in a delayed $\mathrm{T}$-maze alternation paradigm. In this study (outlined above), when a $5 \mathrm{~min}$. delay was imposed between Phase 1 and Phase 2 of the T-maze alternation test, $\mathrm{nbM}$ lesioned rats showed a retention deficit greater than shamoperated controls. The administration of $0.06 \mathrm{mg} / \mathrm{kg}$ physostigmine prior to the test procedure prevented the lesion-induced retention deficit.

It should be noted however, that there are constraints on the general efficacy of physostigmine in reversing lesion induced deficits. Because physostigmine is an acetylcholinesterase inhibitor, it is dependent on the presence of acetylcholine for its cholinolytic action. Thus the efficacy of physostigmine is dependent upon the integrity of the cholinergic neurons. When the majority of cholinergic neurons have been destroyed by experimental lesions or the progress of a degenerative disease process (eg. Alzheimer's disease), the efficacy of physostigmine or any other compound (eg. 4-aminopyridine) which relies on the presence of cholinergic neurons can be expected to diminish, as it would in humans.

The ability of several other cholinergic compounds to enhance memory in rats have been examined. ${ }^{54,55.56}$ In general, compounds found to enhance retention test performance of unlesioned rats are also effective in alleviating nbM-lesion induced memory deficits. The results of experiments using 4-aminopyridine and oxotremorine administered immediately following the acquisition of a passive avoidance response are shown in Figures 4 and 5 . Both drugs enhanced the retention test perfor-

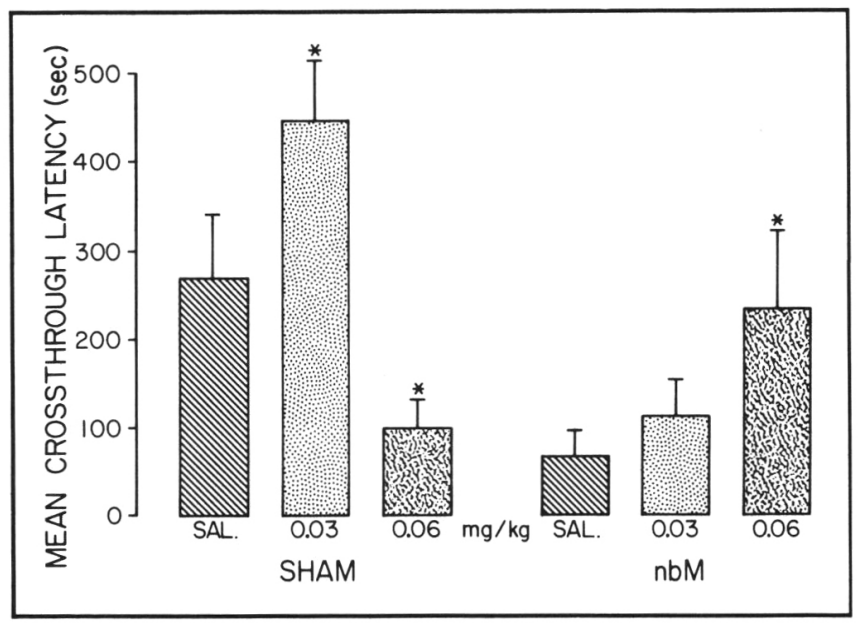

Figure 3 - Effects of post-training administration of two physostigmine on the 72 hour retention of passive avoidance in $n b M$-lesioned and sham operated rats. ${ }^{*} v$ s. saline, ps $<0.01$ 
mance of lesioned as well as sham-operated rats, but the effective doses varied as a function of the compound used and the lesion status of the animals. As was the case with physostigmine, larger doses of 4-aminopyridine were required to enhance retention test performance in nbM-lesioned rats, than in sham-operated controls. The reverse was true with post-trial administration of the agonist, oxotremorine. The dose of oxotremorine which was most effective when administered to control rats was either ineffective when administered to nbM lesioned rats or led to a worsening of retention test deficits $(0.02 \mathrm{mg} / \mathrm{kg}$ data not shown). Recently Ridley et al ${ }^{57}$ have reported that another cholinergic receptor agonist, arecoline, significantly improves the visual discrimination learning deficits which arise in marmosets following lesions of the nbM. In addition, once the discrimination was learned, nbM lesioned marmosets were found to be more sensitive to the disruptive effects of low dose scopolamine than sham operated controls. The lesion-induced changes in the dose response relationship for scopolamine and for cholinomimetics with different modes of action strongly suggest that the memory impairments produced by nbM lesions are due to lesion-induced changes in cortical cholinergic activity rather than being caused by non-specific neural damage. Furthermore, the nbM-lesion induced deficits in frontal cortex cholinergic function appears to be the site of action of cholinomimetics, since in a recent preliminary study we have found that gross lesions of the frontal cortex in nbM damaged rats block the memory enhancing properties of physostigmine.

Enough compounds have been tested to entertain some general conclusions and pose the following testable hypothesis: the dose response curve for compounds with a principally presynaptic mode of action is shifted to the right in nbM lesioned rats, while the dose response curve for drugs with a postsynaptic locus of activity may be shifted to the left. A test of such a hypothesis would lead to valuable insight when contemplating pharmacological treatment strategies for patients with Alzheimer's disease.

The results of the studies reviewed above indicate that almost complete reversal of nbM lesion-induced memory deficits can be achieved in rats by the administration of appropriate doses of drugs which enhance central cholinergic activity. To date, such dramatic reversals of cognitive function have not been achieved when cholinomimetic drugs have been administered

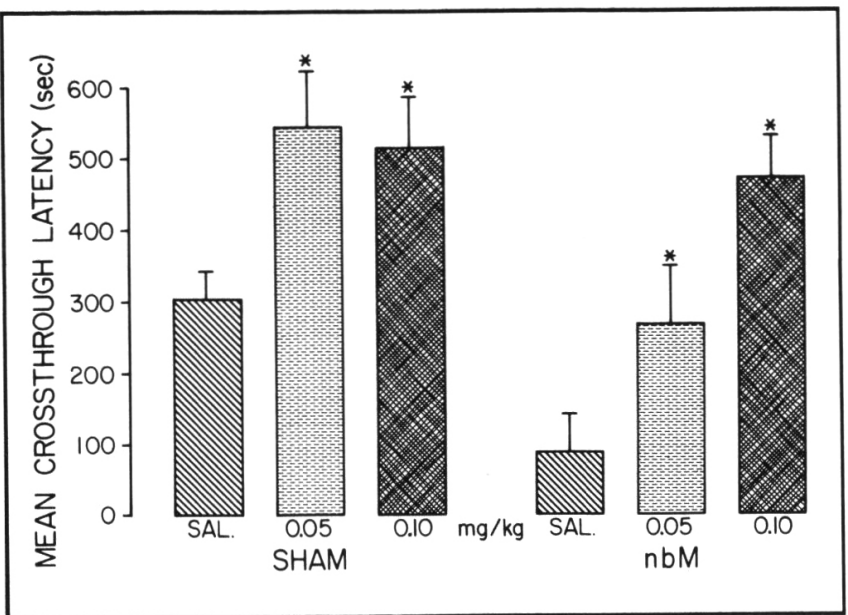

Figure 4-Effect of post-training administration of 4-aminopyridine on the 72 hour retention of passive avoidance in nbM-lesioned and sham operated rats. *vs, saline, $p s<0.01$ to $\mathrm{AD}$ patients. ${ }^{58,59.60}$ One possible reason for the lack of precise agreement between the animal nbM lesion studies and those of AD patients can be the presence of a multiplicity of lesions in AD. Neuropathological studies have repeatedly shown that AD patients suffer from several neurochemical deficits. For example, cortical measures of somatostatin, corticotrophine releasing factor, norepinephrine and several other neurotransmitter related factors are significantly reduced in $\mathrm{AD}$. ${ }^{23,32.33 .61}$ It is therefore possible that the discrepancy between the animal studies and the AD pharmacotherapy results can be resolved by the use of more sophisticated animal model systems where the neurochemical deficits apparent in AD are more closely approximated by the model system.

Towards this end, we have found that cortical noradrenergic and cholinergic systems interact with respect to responsiveness to memory enhancement by physostigmine. Rats with nbM lesions were compared to rats with ascending noradrenergic bundle (ANB) lesions and to rats with combined nbM + ANB lesions. Immediately after the passive avoidance training episode, half of the rats in each lesion condition received a SC. injection of $0.06 \mathrm{mg} / \mathrm{kg}$ physostigmine. As was the case in earlier experiments, ${ }^{15}$ this dose of physostigmine enhanced the 72 hour retention test performance of nbM lesioned rats; this same dose of physostigmine however failed to affect the retention test performance of rats with combined nbM + ANB lesions. Although conclusions regarding this finding must await the sampling of a wide range of doses, these data do suggest that the addition of a noradrenergic lesion to a cortical cholinergic lesion affects the ability of physostigmine to normalize lesion-induced memory deficits. Several other lines of evidence support the notion that central cholinergic and noradrenergic systems interact dynamically. Central catecholamine depletion by $\alpha$-methyl-p-tyrosine administration blocks the passive avoidance memory enhancing properties of the muscarinic agonist, oxotremorine. ${ }^{62}$ Similarly, dorsal NE bundle lesions prevent the development of catalepsy caused by even high doses of arecoline and pilocarpine. ${ }^{63}$ The functional interaction of cortical NE and cholinergic systems is further demonstrated by studies showing that $\alpha$-adrenergic receptor agonists potentiate the responsiveness of cortical neurons to the iontophoretic appliation of $\mathrm{ACh}^{.64}$ These, and several other studies ${ }^{65}$ all support the view that an intact noradrenergic system is a prerequisite for the integrity of at least some central cholinergic functions. If future, more extensive experiments

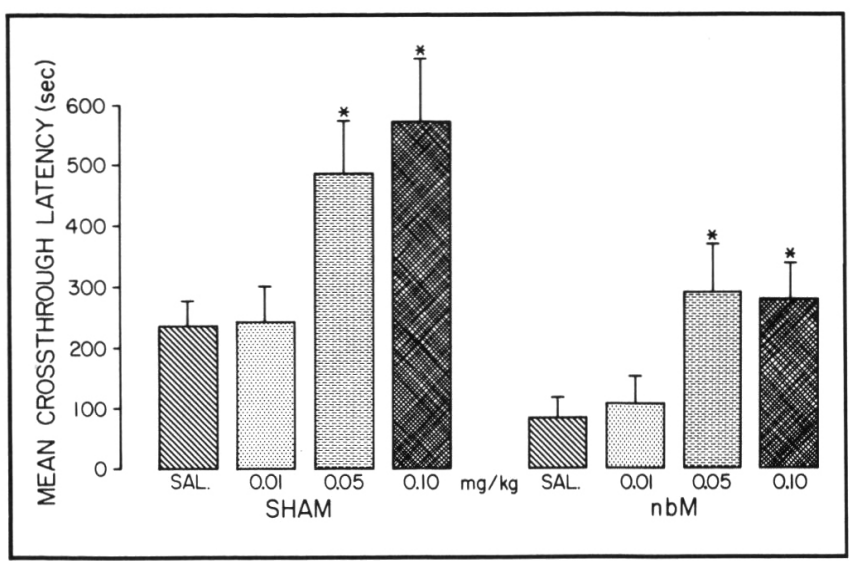

Figure 5 - Effect of post-training administration of oxotremorine on the 72 hour retention of passive avoidance in nbM-lesioned and sham operated rats. *vs. saline, ps<0.01 
confirm that NE lesions significantly alter the effectiveness of cholinergic compounds to influence learning and memory in nbM lesioned rats, it would be expected that the efficacy of physostigmine in AD would be limited not only to cases of AD in which cholinergic degeneration is incomplete, but also to cases of $\mathrm{AD}$ with minimal noradrenergic involvement.

A similar question can be asked regarding the efficacy of physostigmine to enhance retention test performance in animals with somatostatinergic deficits. Rats received either saline or a $150 \mathrm{mg} / \mathrm{kg}$ dose of cysteamine 24 hours prior to passive avoidance training. Several earlier experiments had shown that this dose of cysteamine produced a $50 \%$ reduction in cortical somatostatin stores, and that these reductions lasted 48-72 hours. Immediately following passive avoidance training different groups of rats received subcutaneous injections of $0,0.03$, 0.06 , or $0.12 \mathrm{mg} / \mathrm{kg}$ physostigmine. When tested for the retention of passive avoidance 72 hours later, it was found that, unlike noradrenergic depletions, somatostatin deficits did not substantially alter the dose response relationship for physostigmine. Similarly, the reduction of cortical somatostatin stores did not add to the retention deficits which are apparent in nbM lesioned rats. It remains to be seen whether the combination of cholinergic and somatostatinergic lesions affects the dose response function for cholinergic drugs such as physostigmine.

It seems clear that animal models such as those discussed above can be used to gain insight into the factors which determine the efficacy of different pharmacological agents to reverse functional deficits caused by lesions typical of AD. Viewed from a clinical perspective, the results of the studies outlined above suggest that new therapeutic strategies must be designed which accommodate the diverse neurochemical deficits seen in the AD population by restoring the functional integrity of a number of affected systems.

\section{Use of fetal tissue transplants in the alleviation of lesion-induced deficits}

Numerous laboratories are engaged in investigation of the use of fetal tissue transplants as potential tools for the treatment of neurodegenerative diseases. Animal model systems have shown that central nervous tissue transplants are not only feasible but that such transplants can have functional consequences. This literature has been reviewed recently in several publications and monographs ${ }^{66}$ and will not be reiterated here. Those studies which have investigated the effects of neural tissue transplants on the behavioral deficits caused by cholinergic lesions will be the subject of this review.

One of the first reports of transplant induced reversal of behavioral deficits in cholinergically lesioned rats, showed that grafts of embryonic septal origin placed into the hippocampus of fimbria/fornix lesioned rats reversed the T-maze alternation deficits resulting from the lesion procedure ${ }^{67}$ Behavioral recovery of function was accompanied by the return of acetylcholinesterase staining patterns in the denervated hippocampus. These findings have now been replicated by several authors and have been extended to a variety of behaviors. ${ }^{68,69}$ More recently Dunnett et $\mathrm{al}^{70}$ and Fine et $\mathrm{al}^{71}$ have shown that fetal septal cell suspension grafts into the cortex of unilaterally nbM-lesioned rats are also effective in reversing nbM-lesion induced behavioral and neurochemical deficits. A recent study in our laboratory using bilaterally lesioned rats has confirmed the transplant induced reduction of cortical neurochemical deficits resulting from nbM lesions. In our study however, the neurochemical deficit reduction was not accompanied by a concurrent alleviation of learning and memory deficits. Procedural changes and improvements may well lead to simultaneous behavioral and neurochemical deficit reduction in bilaterally lesioned rats. Despite these preliminary results the application of neural transplant technology to $\mathrm{AD}$ awaits the resolution of many issues, not the least of which are the moral issues regarding the source of the transplanted tissue. Furthermore, just as pharmacological single transmitter repletion strategies suffer from the fact that many transmitter systems are involved in $A D$, the transplantation of cholinergic cells in AD may be inadequate without supplementation by cells expressing a variety of transmitter characteristics.

\section{The use of neurotrophic factors and growth promoting agents to alleviate lesion-induced deficits}

Appel ${ }^{72}$ and Hefti ${ }^{73}$ suggested that deficits in brain neurotrophic factors such as nerve growth factor, could provide the basis for many neurodegenerative diseases such as AD, Parkinson's disease and ALS. The role of neurotrophic factors in brain has recently been reviewed by several authors. ${ }^{74.75 .76}$ Although the evidence implicating trophic factor or growth promoting factor abnormalities in $\mathrm{AD}$ is sparse, ${ }^{77}$ the possibility has not been extensively studied. Still, the exogenous administration of nerve growth promoting factors can enhance or prompt recovery from experimentally induced insults. Nerve growth factor (NGF) is the best characterized growth promoting factor in the CNS. It has been repeatedly shown that NGF can promote the post-lesion recovery of some neurochemical deficits, with a particular affinity for restoration of cholinergic markers. ${ }^{78.79 .80}$ Furthermore, NGF, when applied to the cerebral cortex of rats, is preferentially picked up by cholinergic nerve terminals and is transported retrogradely to cell bodies in the nbM. ${ }^{81}$ In our study of the effects of NGF in nbM lesioned rats, we administered $N G F$ intra-ventricularly to rats which had received excitotoxic lesions of the nbM. NGF (5 ug/rat) administered to rats on days $2,4,8$ and 12 post lesion failed to effect the cortical lesion-induced deficits when the rats were sacrificed two weeks after the lesion, but at the 6 week postlesion intervals cortical CAT and ACHE deficits were reduced by approximately $50 \%$ (see Figure 6 ) ${ }^{80}$ Essentially similar data was obtained by us and Hefti et $\mathrm{al}^{78}$ in the hippocampus when NGF was administered to rats with fimbria/fornix lesions. A number of other studies showing potentially positive effects of NGF have been reported, including the work of Stein and Will ${ }^{82}$ who have shown that NGF administration can also lead to improvements in behavioral indices of experimentally lesioned animals. ${ }^{83}$

Gangliosides constitute another category of growth promoting factors which have received increasing attention. There are now a number of clinical and experimental studies which show that the exogenous administration of gangliosides, especially the monosialoganglioside $G M_{1}$ can enhance central nervous system recovery following brain injury. ${ }^{84-91}$ In general the results of the studies with gangliosides are similar to those with NGF. Thus, for example, the administration of gangliosides to animals with fimbria/fornix lesions has been shown to result in significant enhancement of cholinergic activity in the denervated hippocampus. ${ }^{87.89}$ Furthermore, ganglioside-induced recovery of neurochemical parameters is accompanied by recov- 
ery of lesion-induced behavioral deficits. Of potentially significant relevance to $A D$, Cuello et a ${ }^{92}$ have shown that the retrograde degeneration of $\mathrm{nbM}$ neurons caused by lesions of the cerebral cortex, can be prevented by the postlesion administration of the ganglioside $\mathrm{GM}_{1}$.

Unlike NGF, the actions of the gangliosides do not appear to be transmitter system specific. For example there is ample evidence that the exogenous administration of gangliosides can promote recovery from cholinergic as well as dopaminergic damage.$^{90.91}$ Furthermore, there is some evidence to suggest that in addition to the long-term promotion of recovery processes, gangliosides may play a role in limiting the extent of neural injury, by an anti-inflamatory / anti- $\mathrm{Na}^{+}, \mathrm{K}^{+}$-ATPase loss action. ${ }^{93}$ Thus, although still in its infancy, there is reason to believe that growth promoting factors such as NGF, $\mathrm{GM}_{1}$, or any number of other trophic factors now under study, may have a place in the etiology or treatment of $A D$.

The experiments outlined above show that there is a place for animal models of Alzheimer's disease. These studies have shown that despite the absence of naturally occurring AD in animals and the lack of agents and experimental procedures which can mimic AD in lower species, some aspects of the disease can be reproduced experimentally in animals. Additionally the pharmacological studies have shown that experimentally-induced behavioral deficits in some neurotransmitter systems can be reversed by appropriate pharmacological manipulations, and that insight into the appropriate pharmacological treatment strategy for patients may be gleaned from experiments which attempt to reproduce the known deficits present in $\mathrm{AD}$. There is also good reason to believe that some of the neurochemical and neuroanatomical deficits may be amenable to restoration either by the use of techniques such as neural grafting, or by the use of growth promoting and neurotrophic factors. It is hoped that the application of the results of animal model studies to the clinical milieu may not only lead to more efficacious treatments for $\mathrm{AD}$, but may provide even greater impetus to the development of model systems which more closely approximate the disease process.

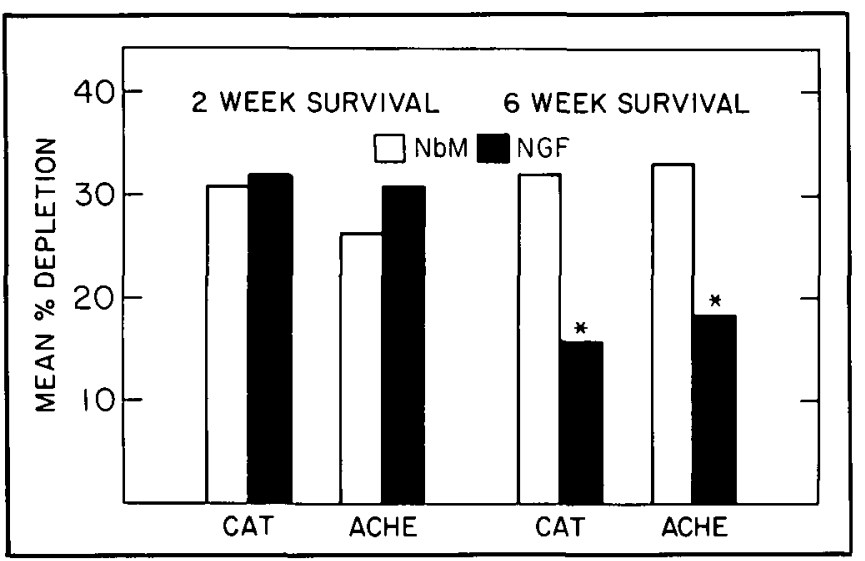

Figure 6 - Effect of intraventricular administration of NGF on \% depletion of choline acetyltransferase (CAT) and acetylcholinesterase (ACHE) in nbM lesioned rats. At six weeks survival CAT values were $0.63,0.43$, and 0.53 (p.mol. ACH/mg. prot./min.) for sham, lesioned and NGF treated rats respectively. ACHE values for the three groups were $26.4,17.6$ and 21.8 (n.mol./mg.prot./min.). ${ }^{*} v s \mathrm{nbM}$, ps $<0.01$

\section{REFERENCES}

1. Whitehouse PJ, Price DL, Struble RG, Clark AW, Coyle JT. Alzheimer's disease and senile dementia: loss of neurons in the basal forebrain. Science 1982; 215: 1237-1239.

2. Candy JM, Perry RH, Perry EK, Irving D, Blessed G, Fairbairn, Tomlinson RL. Pathological changes in the nucleus of Meynert in Alzheimer's disease and Parkinson's disease. J Neurol Science 1983; 54: 277-289.

3. Pearson RCA, Sofroniew MV, Cuello AC. Powell TPS, Eckenstein F, Esiri MM, Wilcock GK. Persistence of cholinergic neurons in the basal nucleus in a brain with senile dementia of Alzheimer's type demonstrated by immunohistochemical staining for choline acetyl-transferase. Brain Research 1983; 289: 370-374.

4. McKinney M, Coyle JT, Hedeen JC. Topographic analysis of the innervation of the rat neocortex and hippocampus by basal forebrain cholinergic system. J Comparative Neurology 1983; 217: 103-121.

5. Johnston MV, McKinney M, Coyle JT. Neocortical cholinergic innervation: A description of extrinsic and intrinsic components in the rat. Experimental Brain Research 1981; 43: 159-172.

6. Wenk H, Volker B, Meyer U. Cholinergic projections from magnocellular nuclei of the basal forebrain to cortical area in rats. Brain Research Reviews 1980; 2: 295-316.

7. Fibiger $\mathrm{HC}$. The organization and some projections of cholinergic neurons of the mammalian forebrain. Brain Research Reviews 1982; 4: 327-388.

8. Davies P, Maloney AJF. Selective loss of central cholinergic neurons in Alzheimer's disease. Lancet 1976; 2: 1403.

9. Perry EK, Perry RH, Blessed G, Tomlinson BE. Necropsy evidence of central cholinergic deficits in senile dementia. Lancet 1976: 2: 143.

10. Perry EK, Tomlinson BE, Blessed G, Bergmann K, Gibson PH, Perry RH. Correlation of cholinergic abnormalities with senile plaques and mental test scores in senile dementia. British Medical Journal 1978; 2: 1457-1459.

11. Bartus RT, Dean RL, Beer B, Lippa AS. The cholinergic hypothesis of geriatric memory dysfunction: A critical review. Science 1982; 217: 408-417.

12. LoConte G, Bartolini L, Castamenti F, Marconcini-Pepeu 1, Pepeu G. Lesions of cholinergic forebrain nuclei: Changes in avoidance behavior and scopolamine action. Pharmacology Biochemistry and Behavior 1982; 17: 933-937.

13. Flicker C, Dean RL, Watkins DL, Fisher SK, Bartus RT. Behavioral and neurochemical effects following neurotoxic lesions of a major cholinergic input to the cerebral cortex in the rat. Pharmacology Biochemistry and Behavior 1983; 18: 973-981.

14. Altman HJ, Crosland RD, Jenden DJ, Berman RF. Further characterizations of the nature of the behavioral and neurochemical effects of lesions to the nucleus basalis of Meynert in the rat. Neurobiology of Aging 1985; 6: 125-130.

15. Haroutunian V, Kanof $P$, Davis KL. Pharmacological alleviation of cholinergic lesion induced memory deficits in rats. Life Sciences 1985; 945-952.

17. Bartus RT, Pontecorvo M, Flicker C, Dean RL, Figueiredo JC. Behavioral recovery following bilateral lesions of the nucleus basalis does not occur spontaneously. Pharmacology, Biochemistry and Behavior 1986; 24: 1287-1292.

18. Wenk GL, Olton DS. Recovery of neocortical choline acetyltransferase activity following ibotenic acid injection into the nucleus basalis of Meynert in rats. Brain Research 1984; 293: 184-186.

19. Bartus RT, Flicker C, Dean RL, Pontecorvo M, Figueiredo JC, Fisher SK. Selective memory loss following nucleus basalis lesions: Long term behavioral recovery despite persistent cholinergic deficiencies. Pharmacology, Biochemistry and Behavior 1985; 23: 125-135.

20. Salamone JD, Beart PM, Alpert JE, Iversen SD. Impairment in T-maze alternation following nucleus basalis magnocellularis lesions in rats. Behavioral Brain Research 1984; 13: 63-70.

21. Murray CL, Fibiger HC. Learning and memory deficits after lesions of the nucleus basalis magnocellularis: Reversal by Physostigmine. Neuroscience 1985; 19: 1025-1032. 
22. Murray CL, Fibiger HC. Pilocarpine and physostigmine attenuate spatial memory impairments produced by lesions of the nucleus basalis magnocellularis. Behavioral Neuroscience 1986; 100: 23-32.

23. Beal MF, Mazurek MF, Tran VT, Chattha G, Bird ED, Martin JB Reduced numbers of somatostatin receptors in the cerebral cortex in Alzheimer's disease. Science 1985; 229: 289-291.

24. Davies P, Katzman R, Terry RD. Reduced somatostatin-like immunoreactivity in cerebral cortex from cases of Alzheimer's disease Alzheimer senile dementia. Nature 1980; 288: 279-280.

25. Rossor MN, Emson PC, Mountjoy CQ, Roth M, Iversen LL. Reduced amounts of immunoreactive somatostatin in the temporal cortex in senile dementia of Alzheimer's type. Neuroscience Letters 1980; 20: 373-377.

26. Bennett-Clarke C, Romagnano MA, Joseph SA. Distribution of somatostatin in the rat brain: telencephalon and diencephalon Brain Research 1980; 188: 473-486.

27. Johansson O, Hokfelt T, Elde RP. Immunohistochemical distribution of somatostatin-like-immunoreactivity in the central nervous system of the rat. Neuroscience 1984; 13: 265-339.

28. Haroutunian V, Mantin R, Campbell GA, Tsuboyama GK, Davis KL. Cysteamine-induced depletion of central somatostatin-like immunoactivity: Effects on behavior, learning, memory and brain neurochemistry. Brain Research (in press).

29. DiLiberato EJ, DiStefano V, Smith JC. Mechanisms and kinetics of the inhibition of dopamine-B-hydroxylase by 2-mercaptoethylguanidine. Biochemical Pharmacology 1973;22:2961-2972.

30. Vecsei L, Kiraly C, Bollok I, Nagy A, Verga J, Penke B, Telegdy G. Comparative studies with somatostatin and cysteamine in different behavioral tests on rats. Pharmacology, Biochemistry and Behavior 1984; $21: 833-837$.

31. Bakhit C, Swerdlow NR. Behavioral changes following central injection of cysteamine in rats. Soc Neuroscience Abst 1984; 10 : 182.

32. Cutler NR, Haxby JV, Narang PK, May C, Burg C, Reines SA Evaluation of an analogue of somatostatin (L363, 586) in Alzheimer's disease. New England J Medicine 1985; 312: 725.

33. Adolfsson R, Gottfries CG, Roos BE, Winblat B. Changes in the brain catecholamines in patients with dementia of Alzheimer's type. British J Psychiatry; 1979: 135: 216-223.

34. Benton JS, Bowen DM, Allen SJ, Haan EA, Davison N, Neary D, Murphy RP, Snowden JS. Alzheimer's disease as a disorder of isodendritic core. Lancet 1982; 20: 456.

35. Perry EK, Tomlinson BE, Blessed G, Perry RH, Cross AJ, Crow TJ. Neuropathological and biochemical observations on the noradrenergic system in Alzheimer's disease. J Neurol Science 1981; 51: 279-337.

36. Mason ST. Noradrenaline in the brain: Progress in theories of behavioral function. Progress in Neurobiology 1981; 16:262-303.

37. McNaughton N, Mason ST. The neuropsychology and neuropharmacology of the dorsal ascending noradrenergic bundle-A review. Progress in Neurobiology 1980; 14: 157-219.

38. Gold PE, Zornetzer SF. The mnemon and its juices: Neuromodulation of memory processes. Behavioral and Neural Biology 1983; 38: 151-189.

39. Glavin GB. Stress and brain noradrenaline: A review. Neuroscience and Biobehavioral Reviews 1985; 9: 233-243.

40. Mason ST. Noradrenaline: Reward or extinction? Neuroscience \& Biobehavioral Reviews 1979; 3: 1-10.

41. Mason ST, Fibiger HC. 6-OHDA lesions of the dorsal noradrenergic bundle alters extinction of passive avoidance. Brain Research 1978; 152: 209-214

42. Mason ST, Iversen SD. Effects of selective forebrain noradrenaline loss on behavioral inhibition in the rat. J Comparative and Physiological Psychology 1977; 91: 165-173.

43. Chrobak JJ, DeHaven DL, Walsh TJ. Depletion of brain noradrenaline with DSP-4 does not alter acquisition or performance of a radial-arm maze task. Behavioral and Neural Biology 1985; 44: 144-150.

44. Mason ST, Fibiger HC. Noradrenaline and spatial memory. Brain Research 1978; 156: 382-386.

45. Arnstein AFT, Goldman-Rakic PS. Catecholamines and cognitive decline in aged nonhuman primates. Annals of the New York Academy of Sciences 1985; 444: 218-234.
46. Goldman-Rakic PS, Brown RM. Regional changes G munoamines in cerebral cortex and subcortical structures of aging rhesus monkeys. Neuroscience 1981; 6: 177-187.

47. Gold PE, Murphy JM. Brain noradrenergic responses to training and to amnestic frontal cortex stimulation. Pharmacology, Biochemistry and Behavior 1980, 13: 257-263.

48. Gold PE, McGaugh JL. Hormones and memory. In: Miller LH, Sandman CA, Kastin AJ, eds. Neuropeptide Influences on the Brain and Behavior 1977; 127-143.

49. Welsh KA, Gold PE. Brain catecholamines and memory modulation: Effects of footshock, amygdala implantation, and stimulation. Behavioral and Neural Biology 1985; 43: 119-131.

50. Gold PE, Robertson NL, Delanoy, RL. Post-training brain catecholamine levels: lack of response to water-motivated training. Behavioral and Neurobiology 1985; 44: 425-433.

51. Haroutunian V, Riccio DC. Effects of arousal conditions during reinstatement treatments upon learned fear in young rats. Deve!opmental Psychobiology 1977; 10: 25-32.

52. Gold PE, van Buskirk RB. Facilitation of time-dependent memory processes with post-trial epinephrine injections. Behavioral Biology 1975; 13: 145-153.

53. Levy A, Brandies R, Dachir S, Luz S, Karton Y, Heldman E, Pitte Z, Fisher A. Reversal of AF64A-induced memory impairment by cholinergic compounds. Neuroscience Abstracts 1985, 11: 2, 875.

54. Haroutunian V, Barns E, Davis KL. Cholinergic modulation of memory in rats. Psychopharmacology 1985; 87: 266-271.

55. Flood JS, Landry DW, Jarvik ME. Cholinergic receptor interactions and their effects on long-term memory processing. Brain Research 1981, 215: 177-185.

56. Flood JS, Smith GE, Cherkin A. Memory retention: Potentiation of cholinergic drug combinations in mice. Neurobiology of Aging 1983; 4: 37-43.

57. Ridley RM, Murray TK, Johnson JA, Baker HF. Learning Impairment following lesion of the basal nucleus of Meynert in marmoset: Modification by cholinergic drugs. Brain Research 1986; 376: 108-116.

58. Mohs RC, Davis BM, Johns CA, Mathe AA, Greenwald BS, Horvath TB, Davis KL. Oral physostigmine treatment of patients with AD. Amer J Psychiatry 1985; 142: 28-33.

59. Haroutunian V, Davis KL, Davis BM, Horvath PB, Johns CA, Mohs RC. The study of cholinomimetics in Alzheimer's disease and animal models. Iversen SD. Psychopharmacology: Recent advances and future prospects. Oxford University Press (Oxford, New York, Tokyo) 1985.

60. Hollander E, Mohs RC, Davis KL. Cholinergic approaches to the treatment of Alzheimer's disease. British Medical Bulletin 1986; 42: $97-100$

61. Arai H, Kosaka K, lizuka T. Changes of biogenic amines and their metabolites in postmortem brains from patients with Alzheimertype dementia. J Neurochemistry 1984; 43: 388-393.

62. Huygens $P$, Baratti CM, Gardella JL, Filinger E. Brain catecholamines modification. The effects on memory facilitation induced by oxotremorine in mice. Psychopharmacology 1980;69: 291-294.

63. Mason ST, Fibiger HC. Possible behavioral function for noradrenaline-acetylcholine interaction in brain. Nature 1979; 277 396-397.

64. Waterhouse BD, Moises HC, Woodwark DJ. Alpha-receptormediated facilitation of somatosensory cortical neuronal responses to excitatory synaptic inputs and iontophoretically applied acetylcholine. Neuropharmacology 1981; 20: $907-920$.

65. Vizi ES. Modulation of cortical release of acetylcholine by noradrenaline released from nerves arising from the rat locus coeruleus. Neuroscience 1980; 5: 2139-2144.

66. Gash DM, Collier TJ, Sladek JR Jr. Neural transplantation: A review of recent developments and potential application to the aged brain. Neurobiology of Aging 1985, 6: 131-150.

67. Dunnett SB, Low WC, Iversen SD, Stenevi U, Bjorklund A. Septal transplants restore maze learning in rats with fornixfimbriá lesions. Brain Research 1982; 251: 335-348.

68. Kimble DP, Breiller R, Stickrod G. Fetal brain implants improve maze performance in hippocampal-lesioned rats. Brain Research 1986; 363: 358-363. 
69. Haroutunian V, Kanof PD, Davis KL. Partial behavioral, histochemical and neurochemical restoration of fimbria/fornix lesioninduced deficits by septal transplants (in review).

70. Dunnett SB, Tonilo G, Fine A, Ryan CN, Bjorklund A, Iversen SD. Transplantation of embryonic ventral forebrain neurons to the neocortex of rats with lesions of nucleus basalis magnocellularis-II. Sensorimotor and learning impairments. Neuroscience 1985; 16: 787-797.

71. Fine A, Dunnett SB, Bjorklund A, Iverson SD. Cholinergic ventral forebrain grafts into the neocortex improve passive avoidance memory in a rat model of Alzheimer's disease. Proceedings of the National Academy of Science, USA 1985; 82: 5227-5229.

72. Appel SH. A unifying hypothesis for the causes of amyotrophic lateral sclerosis, parkinsonism and Alzheimer's disease. Annals of Neurology 1981; 10: 499-505.

73. Hefti F. Is Alzheimer's disease caused by lack of nerve growth factor? Annals of Neurology 1983; 13: 109-110.

74. Thoenen H, Edgar D. Neurotrophic factors. Science 1985; 229: 238-242.

75. Shooter EM, Yankner BA, Landreth GE, Sutter A. Biosynthesis and mechanism of action of nerve growth factor. Recent Progress in Hormone Research 1981; 37: 417-466.

76. Thoenen H, Barde Y-A. Physiology of nerve growth factor. Physiological Reviews 1980; 60: 1284-1335.

77. Bass NH. Ganglioside sialic acid as a quantitative neurochemical index of the integrity of synaptic function in cognitive disorders of development and aging. In: Rapport MM, Gorio A, eds. Gangliosides in Neurological and Neuromuscular Function, Raven Press, New York 1981; 29-42.

78. Hefti F, Dravid A, Hartikka J. Chronic intraventricular injections of nerve growth factor elevate hippocampal choline acetyltransferase activity in adult rats with partial septo-hippocampal lesions. Brain Research 1984; 293: 305-311.

79. Mobley WC, Rutkowski JL, Tennekoon GI, Buchanan K, Johnston MV. Choline acepyltransferase activity in spriatum of neo-natal rats increased by nerve growth factor. Science 1985; 229: 284-287.

80. Haroutunian V, Kanof P, Davis KL. Partial reversal of lesioninduced deficits in cortical cholinergic markers by nerve growth factor. Brain Research (in press).

81. Seiler M, Schwab ME. Specific retrograde transport of nerve growth factor (NGF) from neocortex to nucleus basalis in the rat. Brain Research 1984; 300: 33-39.

82. Stein DG, Will BE. Nerve growth factor produces a temporary facilitation of recovery from entorhinal cortex lesions. Brain Research 1983; 261: 127-131.
83. Finger S, Stein DG. Brain damage and recovery: research and clinical perspectives. Academic Press, New York 1982; 227-256.

84. Sabel BA, Slavin MD, Stein DG. GM, ganglioside treatment facilitates behavioral recovery from bilateral brain damage. Science $1984 ; 225: 340-341$.

85. Sabel BA, Dunbar GL, Stein DG. Gangliosides minimize behavioral deficits and enhance structural repair after brain injury. $J$ Neuroscience Research 1984; 12: 429-443.

86. Wojcik M, Ulas J, Oderfeld-Nowak B. The stimulating effect of ganglioside injections on the recovery of choline acetyltransferase and acetylcholinesterase activities in the hippocampus of the rat after septal lesions. Neuroscience 1982; 7: 495-499.

87. Oderfeld-Nowak B, Skup M, Ulas J, Jezierska M, Gradkowska M, Zaremba $M$. Effect of $\mathrm{GM}_{1}$ ganglioside treatment on postlesion responses of cholinergic enzymes in rat hippocampus after various partial deafferentations. J Neuroscience Research 1984; 12: 409-420.

88. Karpiak SE. Ganglioside treatment improves recovery of alternation behavior after unilateral entorhinal cortex lesion. Experimental Neurology 1983; 81: 330-339.

89. Oderfeld-Nowak B, Wojcik M, Ulas J, Potempska A. Effects of chronic ganglioside treatment on recovery processes in hippocampus after brain lesions in rats. In: Rapport MM, Gorio A, eds. Gangliosides in Neurological and Neuromuscular Function, Raven Press, New York 1981; 197-209.

90. Toffano G, Agnati LF, Fuxe K, Aldina C, Consolazione A, Valenti $\mathrm{G}$, Savoini G. Effect of $\mathrm{GM}_{1}$ ganglioside treatment on the recovery of dopaminergic nigro-striatal neurons after different types of lesions. Acta Physiol Scand 1984; 122: 313-321.

91. Agnati LF, Fuxe K, Calza L, Benfenati F, Cavicchioli L, Toffano G, Goldstein M. Gangliosides increase the survival of lesioned nigral dopamine neurons and favour the recovery of dopaminergic synaptic function in striatum of rats by collateral sprouting. Acta Physiol Scand 1983; 119: 347-363.

92. Cuello AC, Stephens PH, Tagari PC, Sofroniew MV, Pearson RCA. Retrograde changes in the nucleus basalis of the rat, caused by cortical damage, are prevented by exogenous ganglioside $\mathrm{GM}_{1}$. Brain Research 1986; 376: 373-377.

93. Li YS, Mahadik SP, Rapport MM, Karpiak SE. Acute effects of $\mathrm{GM}_{1}$ ganglioside: Reduction in both behavioral asymmetry and loss of $\mathrm{Na}^{+}, \mathrm{K}^{+}$-ATPase after nigrostriatal transection. Brain Research 1986; 377: 292-297. 